\title{
The Role of Grain Refiner in the Nucleation of AIFeSi Intermetallic Phases During Solidification of a 6xxx Aluminum Alloy
}

\begin{abstract}
A. LUI (1), P.S. GRANT, I.C. STONE, and K.A.Q. O'REILLY
Primary grain refinement using inoculant additions and intermetallic compound (IMC) phase selection are critical aspects in the solidification of commercial aluminum alloys, controlling the final mechanical properties in service. Although there have been studies which suggest there are explicit interactions between the two phenomena, they have yet to be fully elucidated. Here, through study of intermetallic phase particles extracted from an inoculated casting, key features relating to the nucleation of different intermetallic phases via eutectic reactions are recognized and explained. In particular, rake-like IMCs are identified as initiation points for the deleterious $\beta$-AlFeSi IMC phase in a model $6 \mathrm{xxx}$ series $\mathrm{Al}$ alloy. A mechanism is proposed for how $\mathrm{TiB}_{2}$ inoculant particles, which are commonly used for primary phase refinement, play a role in enhancing the nucleation of intermetallic phases during eutectic reactions at the liquid $/ \alpha-\mathrm{Al}$ interface in the final stages of solidification. The implication of this mechanism is that, after the event of primary grain refinement, any unused $\mathrm{TiB}_{2}$ inoculant particles could be contributing to IMC formation thereby affecting the overall type, size, and distribution of intermetallic phases in the solidified alloy.
\end{abstract}

https://doi.org/10.1007/s11661-019-05447-y

(C) The Author(s) 2019

\section{INTRODUCTION}

INTERMETALLIC phases form towards the latter stages of solidification in aluminum alloys from the interaction of solute atoms, which are rejected from the growing, relatively dilute, primary $\alpha$-Al grains (crystals) and have become concentrated in the shrinking fraction of intergranular liquid. The type, size, and distribution of these intermetallic phases have considerable influence on the final properties of commercial aluminum alloys, and are arguably more important than the size and morphology of primary $\alpha$-Al grains, which are in any case often recrystallized during downstream processing. Two of the most common solutes in commercial aluminum alloys are $\mathrm{Fe}$ and $\mathrm{Si}: \mathrm{Si}$ is an important alloying element in various wrought alloys and also casting alloys; Fe concentrations of typically 0.6 to 1.0 wt pet arise through the recycling of aluminum scrap, ${ }^{[1]}$

A. LUI is with the Department of Materials, University of Oxford, Oxford University Begbroke Science Park, Woodstock Road, Begbroke OX5 1PF, UK. Contact e-mail: andrew.lui@materials.ox.ac.uk P.S. GRANT and K.A.Q. O'REILLY are with the Department of Materials, University of Oxford, Parks Road, Oxford OX1 3PH, UK. I.C. STONE is with the Brunel Centre for Advanced Solidification Technology, Brunel University London, Uxbridge, Middlesex UB8 3PH, UK.

Manuscript submitted May 17, 2019.

Article published online September 16, 2019 and usually must be diluted by the addition of virgin aluminum to meet alloy specifications. Consequently, one of the most important class of intermetallic phases are those based on AlFeSi. In 6xxx series (dilute Al-Si-Fe-Mg) alloys, metastable cubic $\mathrm{Al}_{8} \mathrm{Fe}_{2} \mathrm{Si}$ and monoclinic $\mathrm{Al}_{5} \mathrm{FeSi}$, designated as $\alpha_{c}-\mathrm{AlFeSi}$ and $\beta$-AlFeSi respectively, form by late stage, high solid fraction solidification reactions ${ }^{[2,3]}$ such as:

$$
\begin{aligned}
& \mathrm{L} \rightarrow \alpha-\mathrm{Al}+\alpha_{c}-\mathrm{AlFeSi} \\
& \mathrm{L} \rightarrow \alpha-\mathrm{A} 1+\beta-\mathrm{AlFeSi}
\end{aligned}
$$

$\beta$-AlFeSi is of particular interest as it is generally considered to be detrimental and forms in facetted, planar morphologies that promote strain inhomogeneity and reduce tensile ductility and toughness. ${ }^{[4,5]} \beta$-AlFeSi may also promote the nucleation of $\mathrm{Al}-\mathrm{Si}$ eutectic in higher $\mathrm{Si}$ concentration casting alloys. ${ }^{[6]}$ Although postsolidification homogenization treatments are used to spherodize or redissolve and then reprecipitate some undesirable intermetallic phases, AlFeSi phases either remain unchanged or only sluggishly undergo solid-state transformations and dissolution. ${ }^{[7]}$ If understanding of the formation mechanisms of $\mathrm{AlFeSi}$ phases during solidification could be improved, there may arise an opportunity to manipulate casting conditions and alloy compositions in such a way as to avoid the most deleterious phases, prolonged postsolidification heat 
treatments, and allow industrial processes to become more tolerant to the use of recycled materials.

\section{A. Inoculation of Aluminum Alloys}

Inoculation, through the addition of grain refiner particles, is common practice in the widely used direct-chill (DC) casting of aluminum alloys. These grain refiner particles act by promoting heterogeneous nucleation of primary $\alpha-\mathrm{Al}$, and the resulting DC cast ingots have a fine $(100$ to $150 \mu \mathrm{m})$, equiaxed grain structure that is relatively insensitive to location within the casting. Compared with columnar grains, equiaxed grains are better able to adjust their positions and orientations as solidification proceeds, and as a result, hot tearing is reduced; the final mechanical properties are also more isotropic. One of the most effective grain refiners is $\mathrm{TiB}_{2}$ particulate, which is usually added into the melt before casting via an Al-Ti-B master alloy with typically a small amount of excess $\mathrm{Ti}^{[8,9]}$

It has been suggested and widely embraced that, because particulate nucleant surfaces have finite size, the condition for growth of any incipient solid on the nucleant surface is not determined by classical heterogeneous nucleation considerations, ${ }^{[10-14]}$ but rather must overcome an energy barrier arising from the Gibbs-Thomson curvature effect, beyond which "freegrowth" of this solid will take place. ${ }^{[15,16]}$ For a small undercooling $\Delta T$, in the region of $0.2 \mathrm{~K},{ }^{[12]}$ the critical radius of the nucleating particle $r^{*}$ is given by ${ }^{[15-18]}$ :

$$
r^{*}=\frac{2 \cdot \gamma_{\mathrm{L} / \mathrm{S}}}{\Delta S_{V} \cdot \Delta T}
$$

where $\gamma_{\mathrm{L} / \mathrm{S}}$ is the free energy per unit area of the liquid/solid interface and $\Delta S_{V}$ is the entropy of fusion per unit volume. This nucleation process, termed athermal heterogeneous nucleation, is deterministic for a given alloy, depending only on the undercooling. ${ }^{[19]}$

As can be readily deduced from Eq. [3], the size of nucleant particles required for the onset of free-growth decreases with increasing undercooling. Added inoculants always have a range of particle sizes and the largest particles in the distribution will be 'activated' first for grain formation. However the majority of $\mathrm{TiB}_{2}$ particles play no part in primary $\alpha$-Al nucleation and the overall efficiency of $\mathrm{TiB}_{2}$ particles is comparatively poor as large undercoolings are generally not achieved (because of recalescence from latent heat of fusion) and the smaller particles are never activated. Particle size analysis and modeling ${ }^{[12,15,20]}$ have shown that the mean $\mathrm{TiB}_{2}$ particle diameter for those contributing to grain initiation is of the order of a few microns, and in a typical Al-Ti-B master alloy although the volume efficiency is at $\sim 40$ pct, the typical number efficiency is only $\sim 1$ pct. ${ }^{[12,20]}$ A large fraction of the remaining 'inactive' inoculant particles are known to be pushed into the interdendritic grain boundary regions as solidification proceeds. ${ }^{[21]}$ It has been speculated that this interdendritic $\mathrm{TiB}_{2}$ that is colocated with increasing $\mathrm{Si}$ and $\mathrm{Fe}$ concentrations rejected by the primary $\alpha$-Al may then act as heterogeneous nucleation sites for $\mathrm{AlFeSi}$ intermetallic phases.

The influence of grain refiner additions, either Al-Ti-B or Al-Ti-C (another grain refiner type), on intermetallic phase selection in binary $\mathrm{Al}-0.5 \mathrm{Fe}$ and ternary Al-0.1Si-0.3Fe alloys has already been reported ${ }^{[22-26]}$. some equilibrium $\mathrm{Al}_{3} \mathrm{Fe}$ (or $\mathrm{Al}_{13} \mathrm{Fe}_{4}$ ) was detected amongst an otherwise majority of metastable $\mathrm{Al}_{6} \mathrm{Fe}$ when the cooling rate was $\sim 5 \mathrm{Ks}^{-1}$ in both directionally solidified samples and small-scale direct-chill castings. In another study, ${ }^{[27]} \alpha_{c}$-AlFeSi was the dominant intermetallic phase (over $\mathrm{Al}_{6} \mathrm{Fe}$ ) when sufficient grain refiner was added to an Al-0.15Si-0.3Fe alloy; there is also evidence that $\beta$-AlFeSi formed among $\alpha_{c}$-AlFeSi when an $\mathrm{Al}-0.6 \mathrm{Si}-0.3 \mathrm{Fe}-0.8 \mathrm{Mg}$ or an $\mathrm{Al}-0.5 \mathrm{Si}-0.3 \mathrm{Fe}-0.4 \mathrm{Mg}$ alloy was inoculated with Al-Ti-B. ${ }^{[28-30]}$

In this study, extracted intermetallic particles from an inoculated model 606x Al-Si-Fe-Mg alloy solidified under industry-standard conditions are examined in detail, in particular the relationship between $\mathrm{TiB}_{2}$ and AlFeSi particles, and a mechanism is proposed for how $\mathrm{TiB}_{2}$ grain refiner particles influence the nucleation of various intermetallic phases in the latter stages of solidification.

\section{EXPERIMENTAL}

A model 606x alloy was prepared in-house ${ }^{[28]}$ with composition Al-0.52 wt pet Si-0.28 wt pet Fe-0.37 wt pet $\mathrm{Mg}$, which was confirmed using optical emission spectroscopy to an error of \pm 2 pct. Two $10 \mathrm{~kg}$ batches of the alloy were melted at $750 \pm 10^{\circ} \mathrm{C}$ and castings were solidified using the TP-1 method, ${ }^{[31]}$ which is a standard method for the aluminum industry. A TP-1 casting has the shape of an inverted cylindrical frustum and for aluminum alloys weighs typically $\sim 300 \mathrm{~g}$. Material located between the 33 and $38 \mathrm{~mm}$ diameter sections of the casting experiences a cooling rate of $\sim 4 \mathrm{Ks}^{-1}$, which is similar to the center of a $180 \mathrm{~mm}$ diameter direct-chill cast ingot. TP-1 castings were made prior to any grain refiner additions as control samples. Subsequent castings were produced with either 'stoichiometric' $\mathrm{A} 1-\mathrm{Ti}-\mathrm{B}$ (A1-2.27 wt pet Ti-0.96 wt pet $\mathrm{B}$ ) or ' $5: 1$ ' Al-Ti-B (Al-5 wt pct Ti-1 wt pct B) grain refiner master alloy, which was added to give an overall concentration of 0.002 wt pet B. A 0.002 wt pet B 5:1 Al-Ti-B addition equates to $0.01 \mathrm{wt}$ pct $\mathrm{Ti}$ addition, which had been previously demonstrated to produce effective grain refinement in the alloy of interest. ${ }^{[28,32,33]}$ The melt was stirred manually every time a casting was made to prevent grain refiner sedimentation. Inoculated castings were produced at various intervals from 2 minutes to 4 hours after the grain refiner addition was first added to the melt.

\section{A. Metallography}

Material from between the 33 and $38 \mathrm{~mm}$ diameter sections of the TP-1 castings was investigated using various characterization and analysis techniques. 
Conventional metallographic samples from the $38 \mathrm{~mm}$ section were first examined using optical microscopy. The polished surface was subsequently anodized using Barker's reagent (1.4 g boric acid, $9 \mathrm{~mL}$ tetrafluoroboric acid, and $194 \mathrm{~mL}$ deionized water) and examined under polarized light. Grain sizes were measured using the mean linear intercept method, averaged from a minimum of 130 measurements in the control alloys and 500 in the inoculated alloys. The $33 \mathrm{~mm}$ section, and also a horizontal cross section of TP-1 castings solidified under the equivalent conditions, were macro-etched using Tucker's reagent $\left(45\right.$ vol pct $\mathrm{HCl}, 15$ vol pct $\mathrm{HNO}_{3}$ and 15 vol pct HF aqueous solution) to examine the macroscale grain structure and distribution.

\section{B. Intermetallic Phase Extraction}

Intermetallic particles were extracted from $\sim 0.4 \mathrm{~g}$ of material taken from near the center of the 33 to $38 \mathrm{~mm}$ section using a butan-1-ol based extraction technique ${ }^{[34]}$. the primary $\alpha$-Al was dissolved, whereas the intermetallic particles and $\mathrm{TiB}_{2}$ grain refiner particles were insoluble and recovered onto a PTFE filter $(0.2 \mu \mathrm{m}$ pore size) for further analysis.

\section{X-ray Diffraction and Quantification of Phase Content}

A portion of the extracted particles was analyzed using X-ray diffraction (XRD) for phase identification in a Siemens D500 X-ray diffractometer that was equipped with a $\mathrm{Cu}-\mathrm{K}_{\alpha} \mathrm{X}$-ray source $(\lambda=1.54 \AA)$. The diffractometer was operated at an acceleration voltage of $40 \mathrm{kV}$, a current of $30 \mathrm{~mA}, 2 \theta$ values between 5 and $75 \mathrm{deg}$, a step size of $0.05 \mathrm{deg}$, and an exposure time of 12 seconds per step. Relative weight fractions between $\alpha_{c}$-AlFeSi and $\beta$-AlFeSi were estimated using a regression curve and nine peak intensity ratios between the two phases ( 3 peaks were chosen from each phase: $22.37,26.53$, and $36.44 \mathrm{deg} 2 \theta$ for $\alpha_{c}$-AlFeSi; 17.03, 20.81, and $28.96 \mathrm{deg} 2 \theta$ for $\beta$-AlFeSi). The regression curve was generated by analyzing mixtures of known proportions (10 to $90 \mathrm{wt}$ pet $\alpha_{c}$-AlFeSi) of pure $\alpha_{c}$-AlFeSi and $\beta$-AlFeSi. ${ }^{[29]}$

\section{Scanning Electron Microscopy}

Some of the extracted particles were examined using scanning electron microscopy, primarily those of the control (noninoculated) and the sample inoculated with 'stoichiometric' Al-Ti-B (without the effect of excess Ti). Chemical analysis was carried out at $10 \mathrm{kV}$ using a JEOL 6480LV SEM that was equipped with energy dispersive $\mathrm{X}$-ray $(\mathrm{EDX})$ and inclined wavelength dispersive $\mathrm{X}$-ray (WDX) detectors. High-resolution images were captured at $4 \mathrm{kV}$ using a JEOL 840F FEG-SEM. As a result of the three-dimensional nature and overall sizes (10s to $100 \mathrm{~s}$ $\mu \mathrm{m})$ of the extracted particles, some of the crucial fine-scale details tended to be lost in conventional imaging, despite the additional depth of field offered by SEM imaging (when compared with optical microscopy). To address this issue, composite image montages are presented to preserve fine-scale, high-magnification details of particular features of interest, while demonstrating the influences of these features on the macroscale morphology and structure of the extracted particles.

\section{RESULTS}

\section{A. Metallography and XRD}

The average grain size at the $38 \mathrm{~mm}$ section was $579 \pm$ 39 and $611 \pm 38 \mu \mathrm{m}$ for the control (noninoculated) TP-1 samples, $186 \pm 6$ and $142 \pm 6 \mu \mathrm{m}$ for the TP-1 samples inoculated with 'stoichiometric' and ' $5: 1$ ' Al-Ti-B after 2 minutes, and $172 \pm 4$ and $122 \pm 3 \mu \mathrm{m}$ for the TP-1 samples inoculated with 'stoichiometric' and '5:1' Al-Ti-B after 4 hours respectively (see Figure 1), confirming that the grain refiner particles were effective in promoting primary $\alpha$-Al grain formation 2 minutes after inoculation and remained so after 4 hours of furnace hold. Phase identification of the extracted particles using XRD suggested that the noninoculated alloy contained predominantly $\alpha_{c}$-AlFeSi (Figure 2(a)) whereas the extracted particles from the inoculated samples consist of mostly $\beta$-AlFeSi (Figure 2(b)). The relative phase content was estimated to be $73 \mathrm{wt}$ pct and $\geq 90 \mathrm{wt}$ pct $\alpha_{c}$-AlFeSi for the control TP-1 samples; 25 and 20 wt pet $\alpha_{c}$-AlFeSi for the TP-1 samples inoculated with 'stoichiometric' and ' $5: 1$ ' Al-Ti-B after 2 minutes; and 21 and $20 \mathrm{wt}$ pct $\alpha_{c}$-AlFeSi for the TP-1 samples inoculated with 'stoichiometric' and ' $5: 1$ ' Al-Ti-B after 4 hours, respectively, supporting the observation that there was a change in the AlFeSi phase selection from mostly $\alpha_{c}$-AlFeSi to mostly $\beta$-AlFeSi after the introduction of Al-Ti-B.

\section{B. SEM of Extracted Particles}

The extracted particles from the casting without inoculation, which were predominantly $\alpha_{c}$-AlFeSi by XRD (Figure 2(a)), tended to be either smooth plates with surface ripples or a framework of curls, as shown in Figure 3(a); sometimes particles exhibited both forms, and in general, it was difficult to recognize the original dendritic/granular outline of the primary $\alpha$-Al around which the interdendritic/intergranular liquid channels, and subsequently the intermetallic particles, shaped. The size of the plates and the curl frameworks varied widely, from $10 \mathrm{~s}$ to $100 \mathrm{~s} \mu \mathrm{m}$. However, the thickness of the plates was always $<1 \mu \mathrm{m}$ and the diameter of the curls was always $\sim 2 \mu \mathrm{m}$.

Conversely, the extracted particles with Al-Ti-B addition, which were mostly $\beta$-AlFeSi as determined by XRD (Figure 2(b)), were commonly rough/angular plates with ledges or steps, or a framework of branches, as shown in Figure 3(b). These characteristics exhibited similar variations comparable to those described in the previous paragraph in overall dimensions (10s to $100 \mathrm{~s} \mu \mathrm{m})$, plate thickness $(<1 \mu \mathrm{m})$, and branch diameter $(\sim 2 \mu \mathrm{m})$. Again, particles sometimes showed both characteristics, and it was difficult to recognize the template provided by the preexisting dendritic/granular shape of the primary $\alpha-\mathrm{Al}$. 

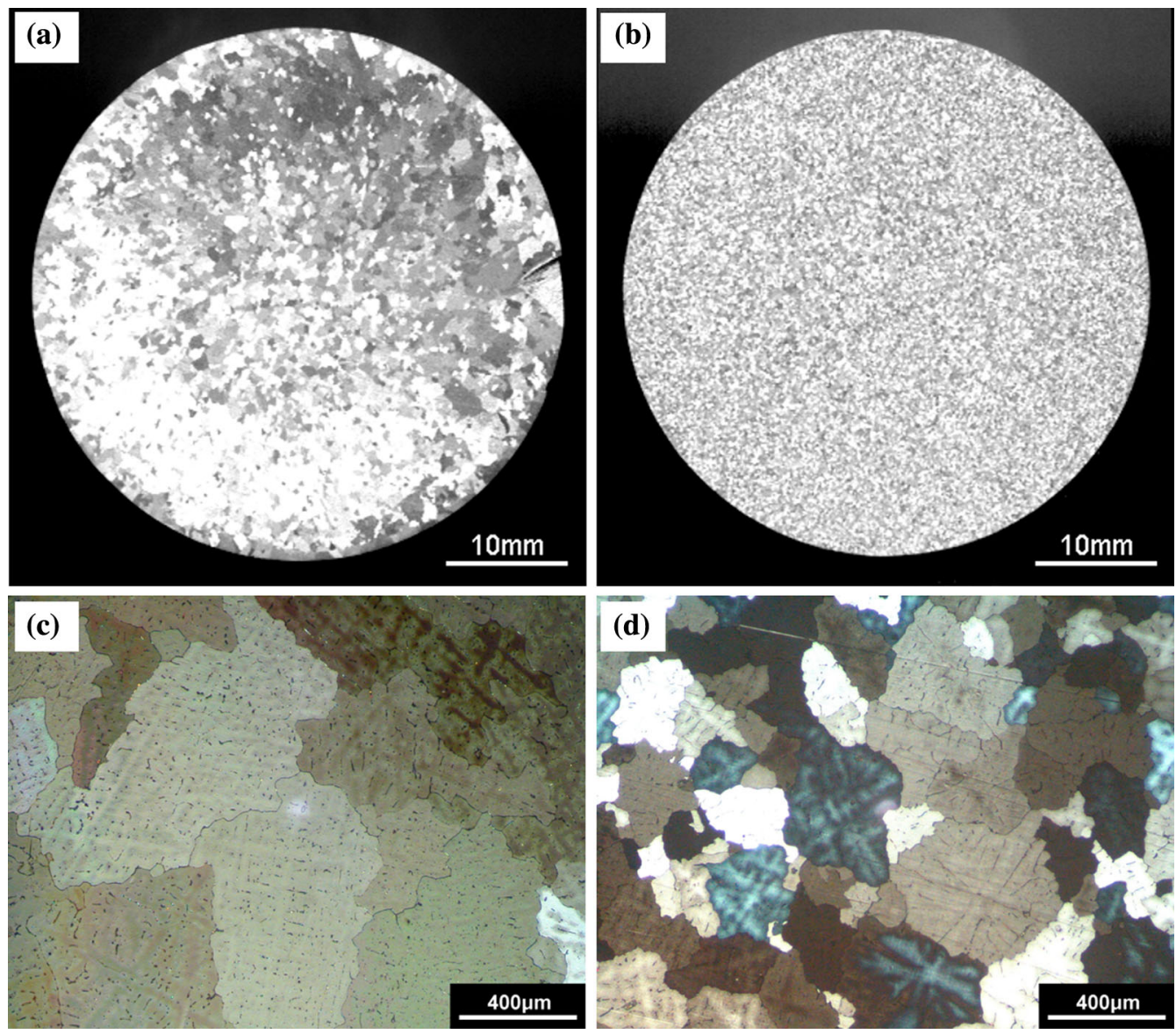

Fig. 1-Photographs of the macroetched $33 \mathrm{~mm}$ cross section of TP-1 castings: $(a)$ noninoculated control sample, and (b) with 'stoichiometric' Al-Ti-B grain refiner; and micrographs of anodized metallographic samples at the 38 mm section under polarized light: (c) noninoculated control sample, and $(d)$ with 'stoichiometric' Al-Ti-B grain refiner.

It was not possible to distinguish reliably between $\alpha_{c}$-AlFeSi and $\beta$-AlFeSi particle type among the extracted particles using EDX/WDX alone because: (i) the sampling volume at $10 \mathrm{kV}$ was much larger than the particle thickness; and (ii) X-ray acquisition geometry was not sufficiently consistent to make robust comparisons. However the characteristic shape of the $\beta$-AlFeSi particles matched well to previous reports in the literature. ${ }^{[37,38]}$ Similar comparisons with the literature for $\alpha_{c}$-AlFeSi were more difficult, and thus confirmation of $\alpha_{c}$-AlFeSi was primarily provided by XRD and that it was distinctly different in shape to $\beta$-AlFeSi.

$\mathrm{TiB}_{2}$ particles were frequently recognized in the images of extracted particles (see Figures 4 and 5(b), etc.), distinctive by their hexagonal, facetted morphology. ${ }^{[39,40]}$ Furthermore the concentrated presence of Ti in these particles was readily confirmed by EDX and the colocation of B by WDX (see Figures 5(b) and 6). Individual $\mathrm{TiB}_{2}$ particles were generally $<1 \mu \mathrm{m}$ in size but were also clustered up to $\sim 10 \mu \mathrm{m}$. Although $\mathrm{TiB}_{2}$ clusters were also observed at the edges of AlFeSi plates, they were mostly associated with recurring, characteristic AlFeSi structures, which are now explained in detail.

Such structures among the $\beta$-AlFeSi particles can be described as resembling a "rake": tines branching laterally from a central platelet. One example is shown in the lower left-hand corner of the $\beta$-AlFeSi particle in Figure 5(a), with a higher magnification view in Figure 5(b) and a further example in Figure 5(c). Often $\mathrm{TiB}_{2}$ particles protruded from the central platelet of the bilateral rake structure (Figures 5(b) and (c)); at times the remainder of the $\beta$-AlFeSi framework branched from one of the tines (Figure 5(a)).

Although the particles extracted from the casting with stoichiometric Al-Ti-B grain refiner were mostly $\beta$-AlFeSi, $\quad \alpha_{c}-\mathrm{AlFeSi}$ was nonetheless present. Figure 7(a) shows an $\alpha_{c}$-AlFeSi particle from the inoculated casting, with two dimensional petal-like plates stemming from a central region of folds/lamellae that was associated with $\mathrm{TiB}_{2}$. This central region is shown at higher magnification in Figure 7(b). A further example of $\mathrm{TiB}_{2}-\alpha_{c}-\mathrm{AlFeSi}$ association, similarly with a three dimensional lamellar structure, is shown in Figure 7(c).

\section{DISCUSSION}

The colocation of $<1 \mu \mathrm{m} \mathrm{TiB}{ }_{2}$ particles, or $\mathrm{TiB}_{2}$ particle clusters, with intermetallic phase particles confirmed the segregation of non- $\alpha$-Al nucleating $\mathrm{TiB}_{2}$ to the interdendritic/intergranular channels towards the 


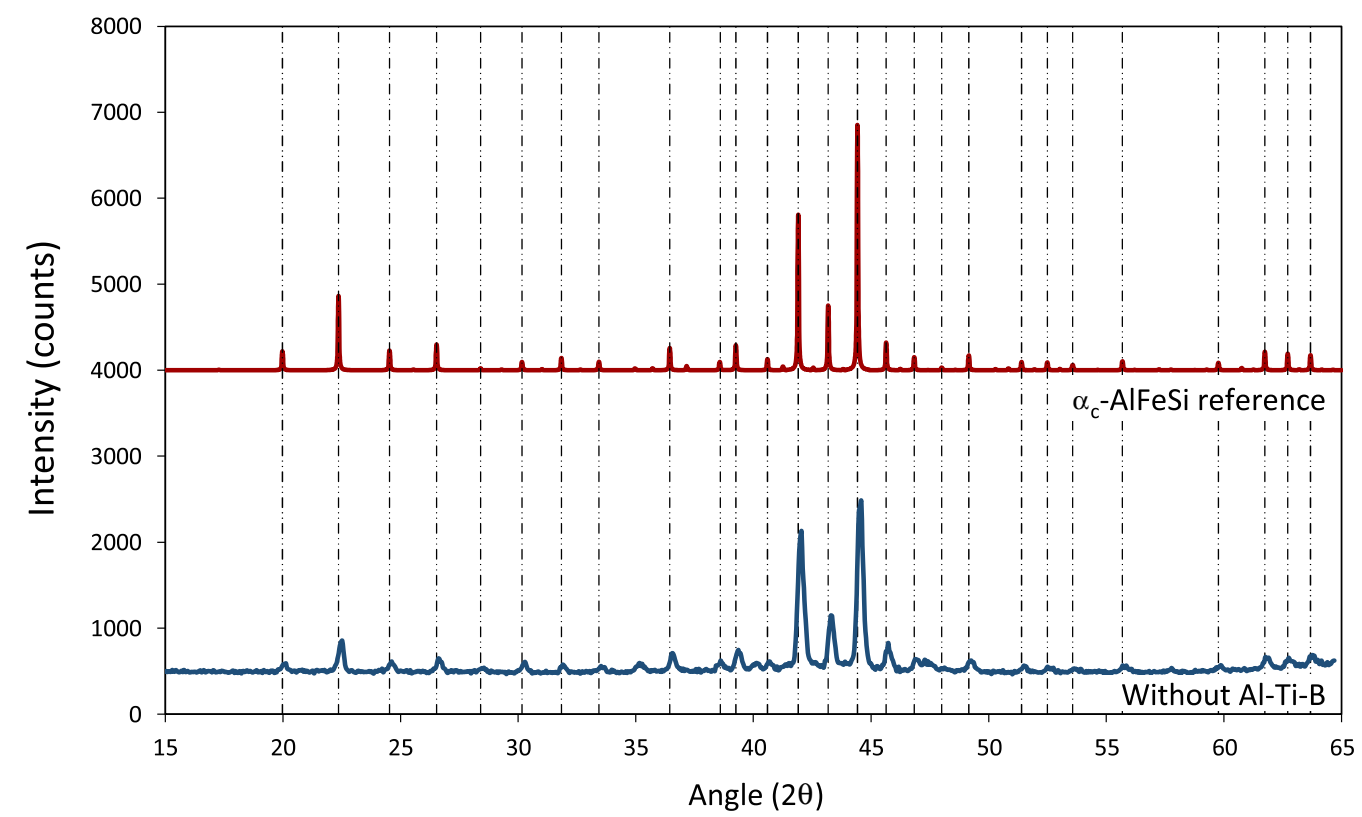

(a)

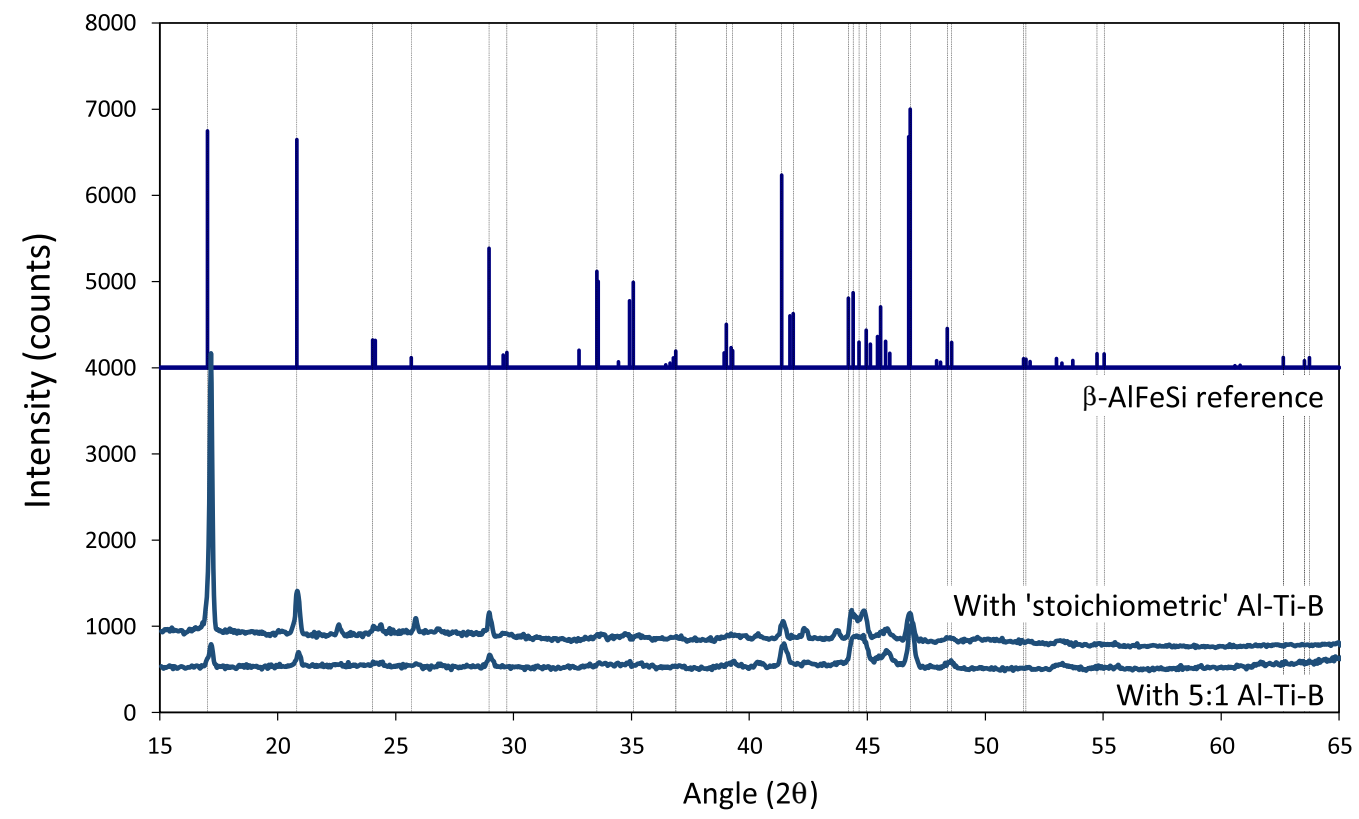

(b)

Fig. 2-XRD patterns of extracted particles from TP-1 castings- $(a)$ without Al-Ti-B addition; and $(b)$ with Al-Ti-B addition. The reference patterns for $\alpha_{c}$-AlFeSi and $\beta$-AlFeSi are shown above each XRD pattern. The reference pattern for $\beta$-AlFeSi was taken from the International Centre for Diffraction Data database (file number 00-082-0546); however, there was no reference pattern for the metastable cubic $\alpha_{c}$-AlFeSi. A theoretical XRD pattern for $\alpha_{c}$-AlFeSi was generated using Powdercell 2.0 software based on the crystal structure proposed in the literature. ${ }^{[35]}$ The enhanced intensity at $17 \mathrm{deg} 2 \theta$ can be explained by the preferred orientation of $\beta$-AlFeSi monoclinic platelets (the 004 reflection), which was attributed to the sample mounting method for XRD. A correction factor was applied to the regression curve when estimating the relative weight fractions to compensate for the enhanced peak intensity observed at $17 \operatorname{deg} 2 \theta^{[36]}$

end of solidification, and that there were significant quantities of redundant $\mathrm{TiB}_{2}$ particles at this concentration. ${ }^{[15,17]}$

The $\alpha_{c}$-AlFeSi particles consisting of two dimensional petal-like plates stemming from a central regions of folds/lamellae are similar to those previously reported $^{[41-43]}$ : the central folded region was the initiation point of the particle, from which the flat petals subsequently grew. Comparable structures of $\mathrm{Al}_{m} \mathrm{Fe}$ associated with 0.2 to $1 \mu \mathrm{m}$ Ti-containing particle agglomerates have also been reported in a commercial purity aluminum alloy. ${ }^{[22]}$

It is more difficult to identify the initiation points for $\beta$-AlFeSi, owing to the distracting complexity of the intermetallic particle framework. Proposed associations between $\beta$-AlFeSi and $\mathrm{TiB}_{2}$ have mostly been based on 


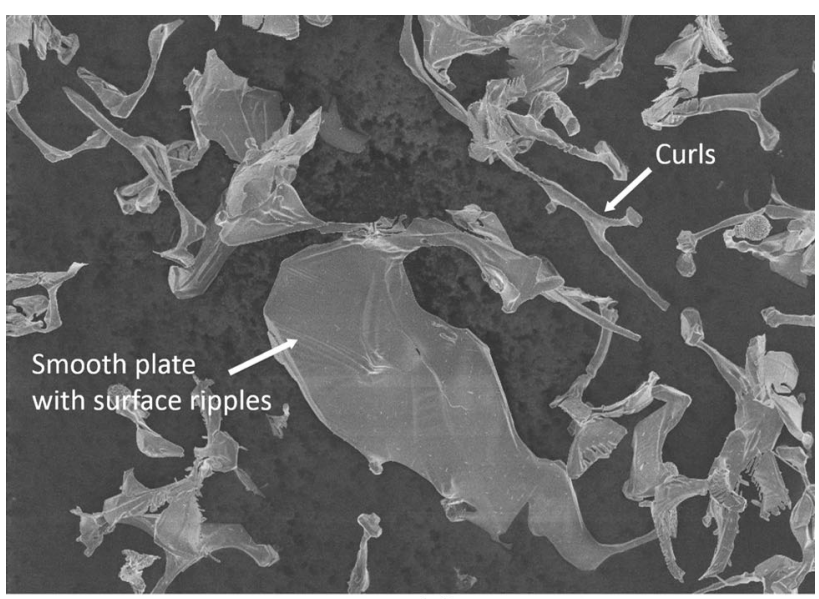

(a)

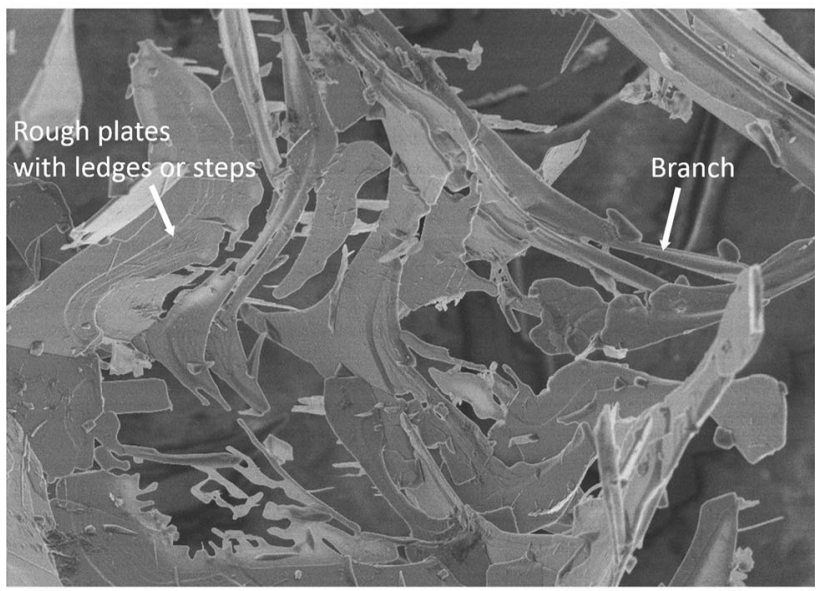

(b)

$\vdash 10 \mu \mathrm{m} \dashv$

Fig. 3-Secondary electron (SE) images of typical extracted particles from $(a)$ alloy without inoculation; and $(b)$ alloy with Al-Ti-B addition.

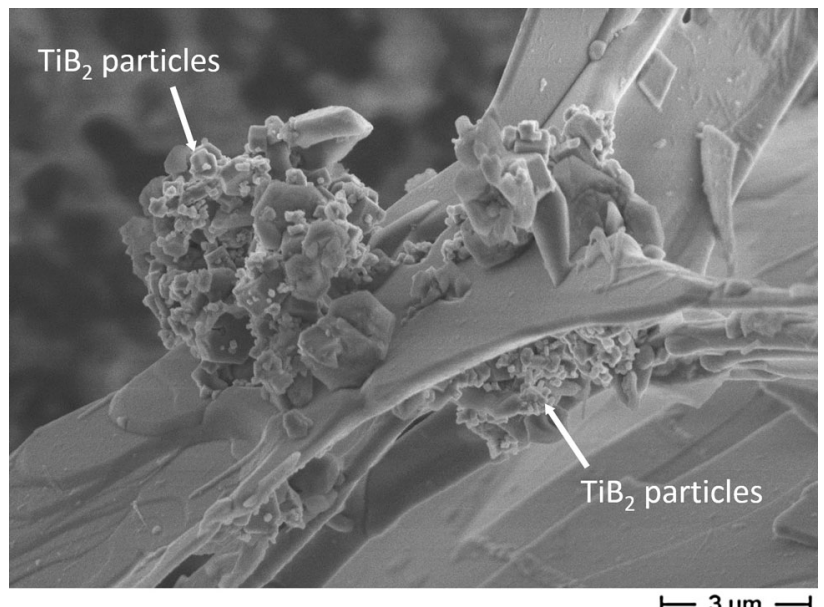

Fig. $4-\mathrm{SE}$ image of $\mathrm{TiB}_{2}$ particles among extracted particles from the alloy with Al-Ti-B additions.

remarking physical contact between them in metallographic cross sections ${ }^{[44,45]}$ or in TEM foil samples, ${ }^{[29,30]}$ both of which were two dimensional observations. One study has suggested that thin plates of $\beta$-AlFeSi grew

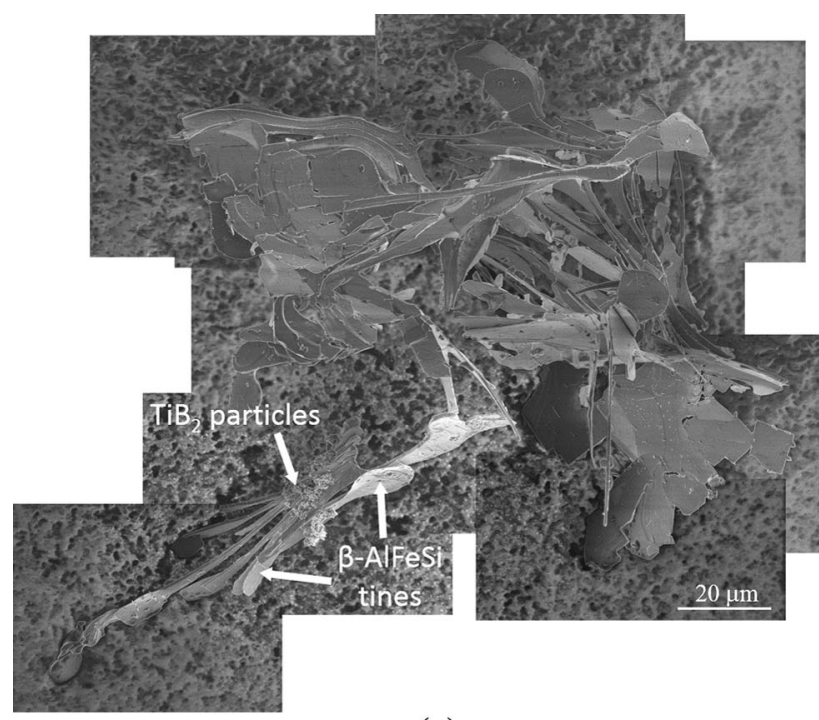

(a)

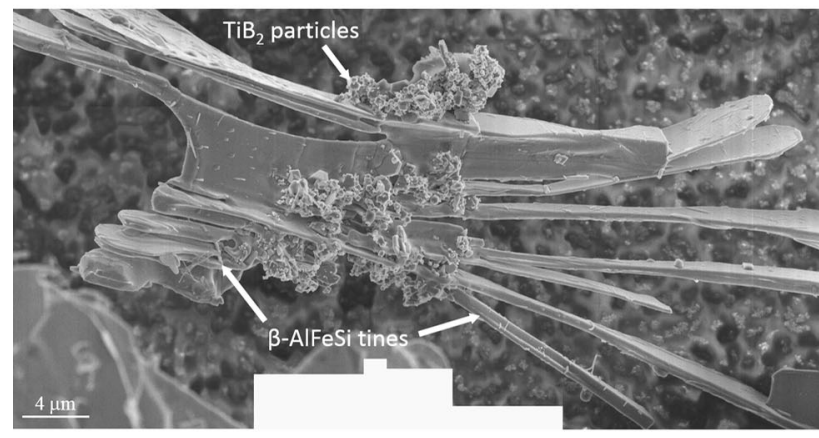

(b)

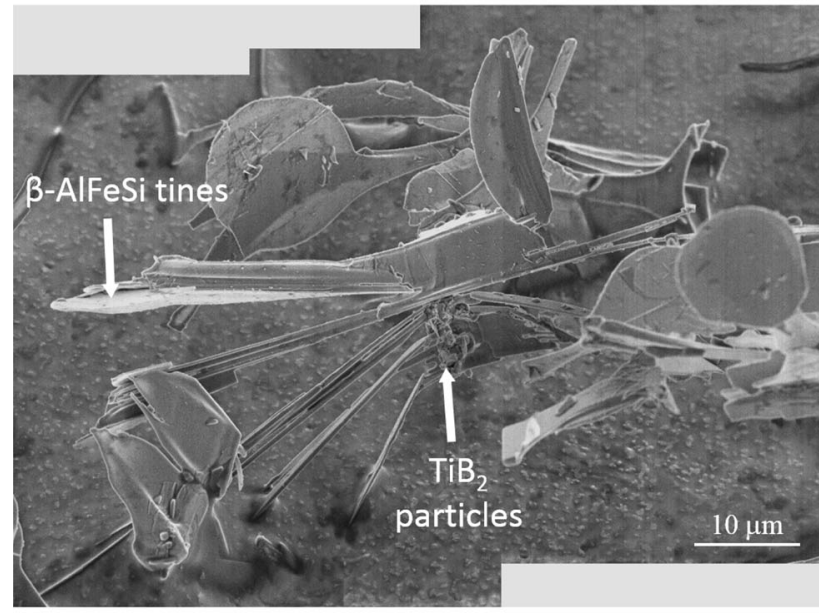

(c)

Fig. 5- SE image of (a) a piece of $\beta$-AlFeSi with a bilateral rake structure on the side; $(b)$ the rake structure in (a) at a higher magnification; and $(c)$ a further example of $\mathrm{TiB}_{2}-\beta$-AlFeSi rake structure. EDX and WDX elemental maps acquired from the $\mathrm{TiB}_{2}-\beta-\mathrm{AlFeSi}$ rake structure in (b) are shown in Fig. 6.

from clustered $\mathrm{TiB}_{2}$ particles, ${ }^{[42]}$ but the intermetallic morphology did not resemble the rake structures repeatedly observed here.

The formation of $\beta-\mathrm{AlFeSi}$, in the absence of $\mathrm{TiB}_{2}$, has been investigated in synchrotron in-situ studies $^{[37,38]}$. 

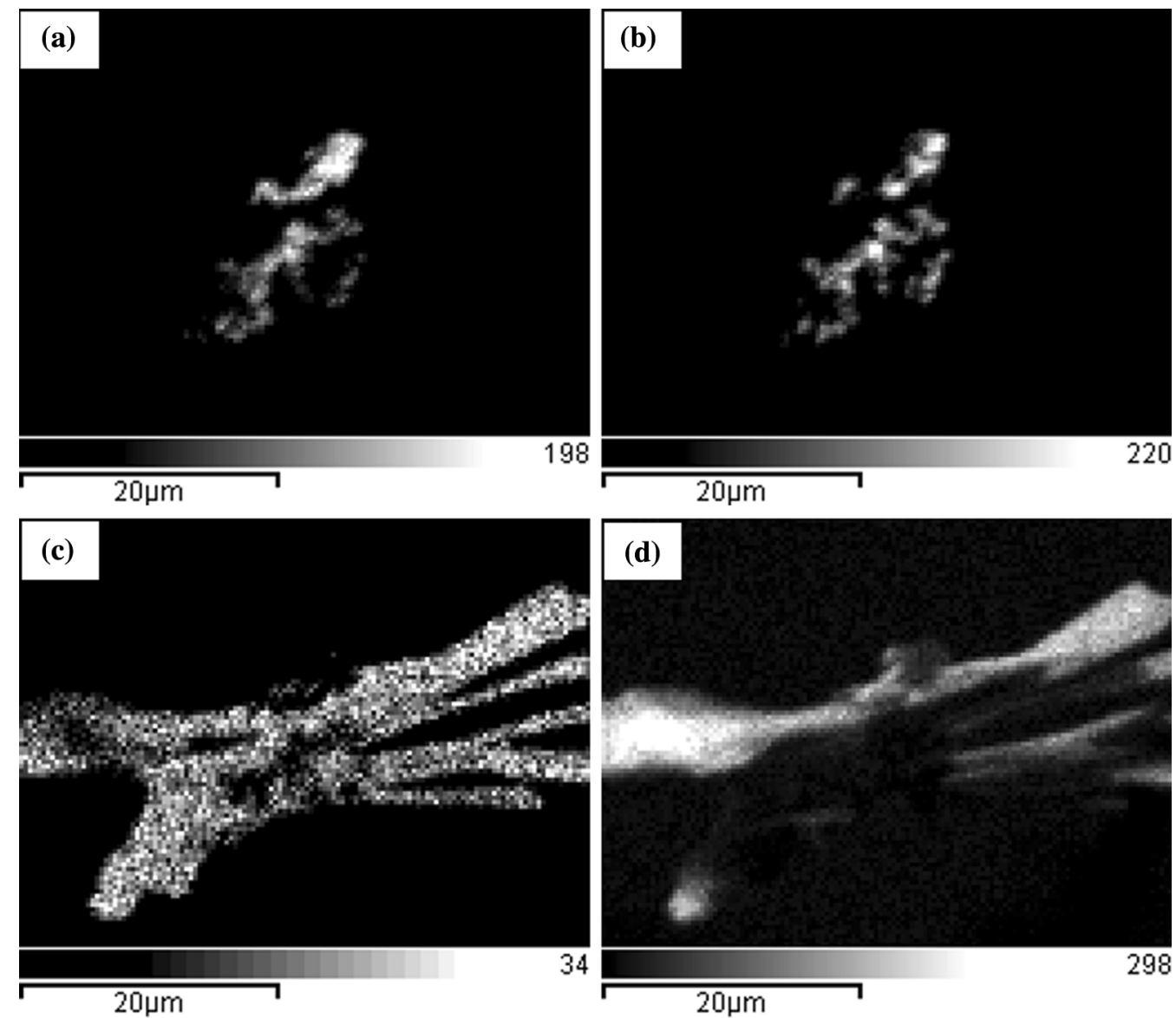

Fig. 6 -Elemental maps acquired from the $\mathrm{TiB}_{2}-\beta$-AlFeSi bilateral rake-like structure shown in Fig. 5(b): (a) Ti EDX map; (b) B EDX map; (c) Fe EDX map; and $(d)$ Si EDX map.

$\beta$-AlFeSi formed either on or very close to $\alpha$-Al or on surface oxide, had a comparatively high initial lateral growth rate $\left(\sim 30 \mu \mathrm{ms}^{-1}\right)$, and wrapped around the primary $\alpha_{c}$-Al dendrites during growth. A period of complex branching events followed, and the growth rate slowed exponentially with time. It can therefore be postulated that the $\beta$-AlFeSi particles shown in Figure 5 first formed somewhere on a cluster of $\mathrm{TiB}_{2}$ particles; this is followed by lateral growth that gave rise to the tines, before branching and further growth.

That $\alpha_{c}$-AlFeSi and $\beta$-AlFeSi had periodic structures (folds in $\alpha_{c}$-AlFeSi and tines in $\beta$-AlFeSi) of similar spacing ( 1 to $2 \mu \mathrm{m})$, and both were associated with $\sim$ $10 \mu \mathrm{m} \mathrm{TiB}{ }_{2}$ particle clusters, suggests that the formation mechanism and conditions for the two intermetallic phases may be similar, i.e. produced via a reaction type that may be catalyzed by $\mathrm{TiB}_{2}$ clusters in the final stages of solidification.

\section{A. $\mathrm{TiB}_{2}$ Particle Influence on Intermetallic Phase Nucleation}

1. Impingement of $\mathrm{TiB}_{2}$ particles by the advancing liquid $/ \alpha$-Al interface

In the presence of potent inoculants $\left(\mathrm{TiB}_{2}\right)$, athermal heterogeneous nucleation is the dominant grain formation phenomenon whereby the largest $\mathrm{TiB}_{2}$ clusters contribute to grain initiation events first. ${ }^{[19]}$ Activation of the smaller $\mathrm{TiB}_{2}$ clusters is subsequently suppressed by the local recalescence from primary $\alpha$-Al solidification, along with any solute suppression effects near the grain due to rejection of solute into a diffusion zone around the grain. ${ }^{[18,46]}$ These inactive clusters remain suspended in the liquid (Figure 8(a)) and eventually, as solidification proceeds, become impinged by the liquid $/ \alpha-\mathrm{Al}$ interface of a primary $\alpha$-Al grain, as it advances after the onset of free growth and latent heat is progressively removed. There could then be three possible outcomes. Firstly the interaction of the liquid $/ \mathrm{TiB}_{2}$ cluster, liquid $/ \alpha-\mathrm{Al}$ and $\mathrm{TiB}_{2}$ cluster $/ \alpha$-Al surface energies (triple point) is such that the $\mathrm{TiB}_{2}$ cluster is engulfed by the liquid $/ \alpha-\mathrm{Al}$ interface. Likewise the same considerations lead to either partial engulfment; or thirdly there is no wetting and the cluster is pushed ahead by the liquid $/ \alpha-\mathrm{Al}$ interface. The effectiveness of $\mathrm{TiB}_{2}$ in nucleating $\alpha$-Al has been attributed to the chemical and crystallographic affinity of $\alpha$-Al to the $\{0001\}$ basal planes of individual $\mathrm{TiB}_{2}$ particles, especially if there is a thin layer of $\mathrm{Al}_{3} \mathrm{Ti}^{[39,47]}$; however it is unlikely that the $\mathrm{TiB}_{2}$ prismatic planes would provide similar affinity. ${ }^{[48]} \mathrm{A} \mathrm{TiB}_{2}$ cluster will have exposed basal and prismatic planes will thus likely to be only partially wetted/engulfed as shown in Figure 8(b). 


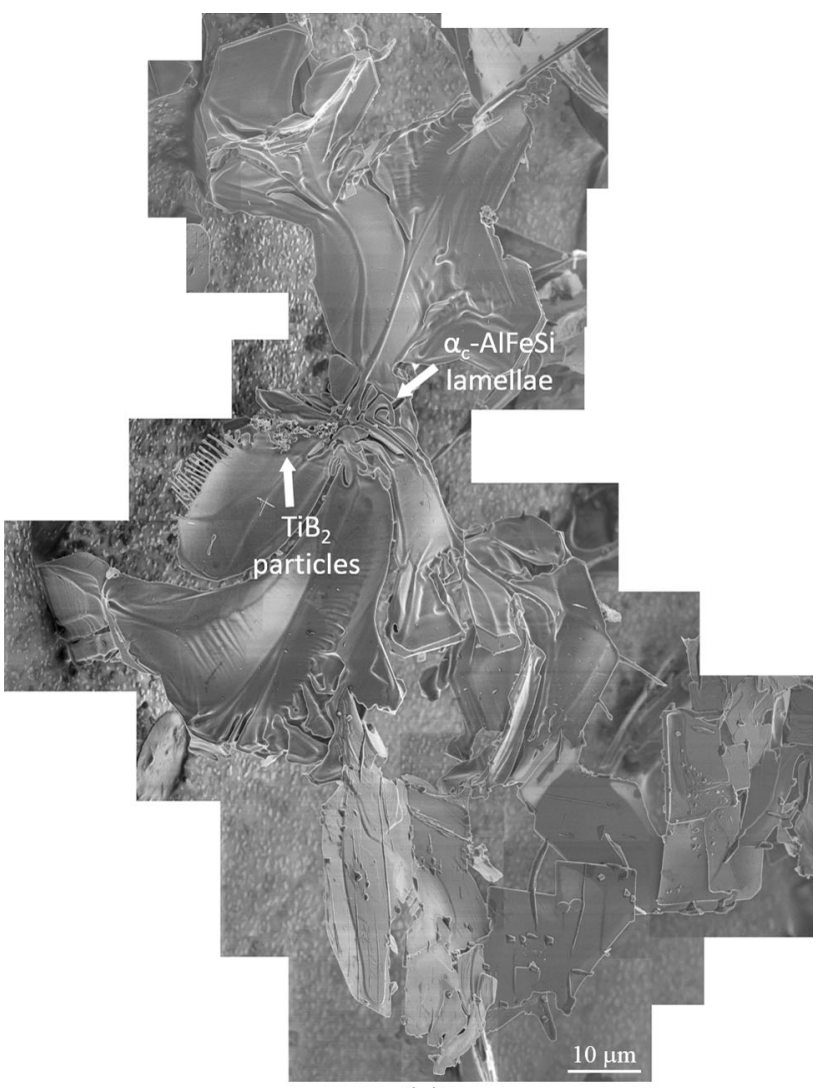

(a)

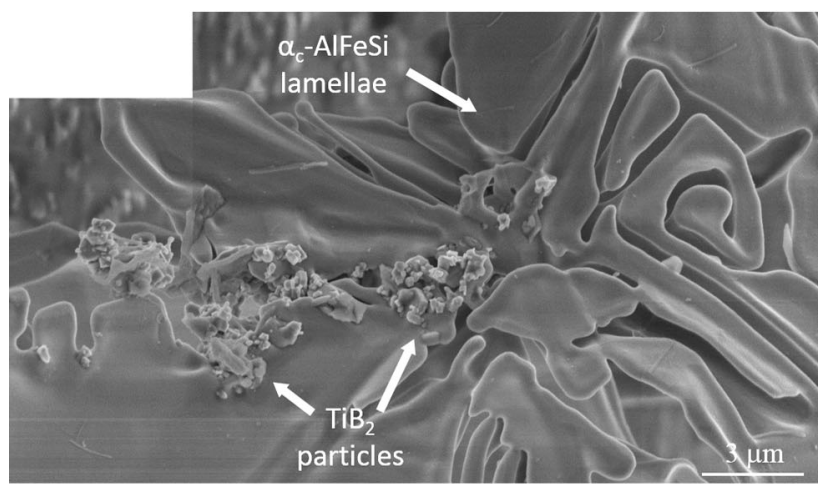

(b)

Fig. 7-SE image of $(a)$ a piece of $\alpha_{c}$-AlFeSi with the lamellar structure in the middle; $(b)$ the lamellar structure in (a) at a higher magnification; and (c) a further example of a $\mathrm{TiB}_{2}-\alpha_{c}$-AlFeSi lamellar structure.

\section{Nucleation of AlFeSi intermetallic phase}

Consider a dilute hypoeutectic Al alloy with a composition $\mathrm{C}_{0}$ and a eutectic composition $\mathrm{C}_{\text {eut }}$, where $\mathrm{C}_{0} \ll \mathrm{C}_{\text {eut }}$. As $\alpha$-Al grains grow, the $\mathrm{Fe}$ and $\mathrm{Si}$ concentrations at the liquid/ $\alpha$-Al interface, $\mathrm{C}_{L / \alpha-A l}$, will rise since, for dilute concentrations, the solid/liquid partition coefficients for both $\mathrm{Fe}$ and $\mathrm{Si}$ in $\mathrm{Al}$ are $<1$, as shown schematically in Figure 9.

The resulting solute profile ahead of the solid/liquid interface can then provide a thermodynamic driving force, as a result of solute undercooling, for the formation of $\mathrm{AlFeSi}$ intermetallic phases. The length

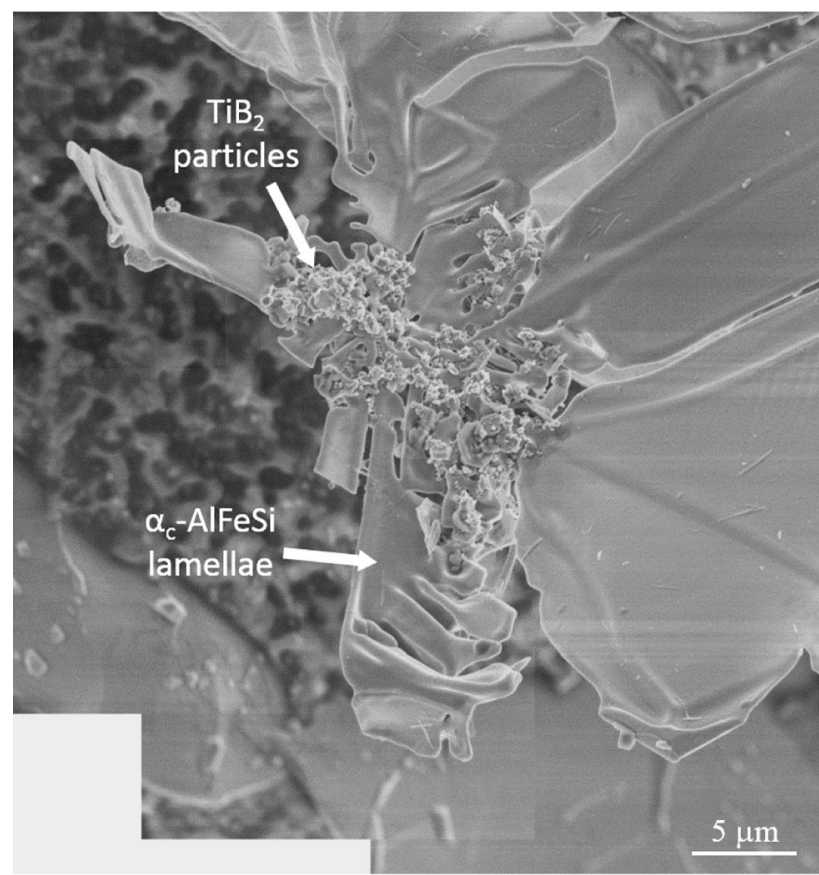

(c)

Fig. 7-Continued.

scale over which solute undercoooling effects act is a function of the solid/liquid interface velocity (which is in turn dependent on the number and size of grains initiated) and the diffusion coefficients of $\mathrm{Fe}$ and $\mathrm{Si}$ in the liquid. In nonequilibrium solidification, the composition of liquid $\mathrm{C}^{*}$ may become larger than $\mathrm{C}_{\text {eut }}$, at $T<T_{\text {eut }}$. The solute-enriched liquid is undercooled by an amount $\Delta T_{\mathrm{AlFeSi}}$ with respect to the $\mathrm{AlFeSi}$ phase liquidus temperature at $\mathrm{C}^{*}$, thus the liquid is now metastable. Assuming the liquid $/ \alpha-\mathrm{Al}$ interface is at equilibrium $\Delta T_{\mathrm{AlFeSi}}$ is given by the difference between $T_{\mathrm{AlFeSi}}^{*}$ and $T_{\alpha-A l}^{*}$. However, recognizing that (i) the temperature is now relatively low and diffusion comparatively slow, and (ii) the noncubic nature of $\beta$-AlFeSi phase, nucleation may be relatively difficult to achieve and thus solute undercooling, $\Delta T_{\mathrm{AlFeSi}}$, of the Si- and Fe-rich liquid may increase further.

At a certain critical value of $\Delta T_{\mathrm{AlFeSi}}$, nucleation of $\mathrm{AlFeSi}$ phase occurs somewhere on the liquid/ $\alpha$-Al interface, ${ }^{[49,50]}$ catalyzed by the $\mathrm{TiB}_{2}$ clusters. It is not certain whether this nucleation event follows a classical or athermal heterogeneous nucleation, although in either case it is likely that the incipient AlFeSi by eutectic reaction will form preferentially on the exposed facets of $\mathrm{TiB}_{2}$ clusters (Figure 8(c)). From directionally grown alloys studied using transmission electron microscopy, ${ }^{[29,30]}$ it was suggested that nucleation of $\beta$-AlFeSi occurred preferentially on $\{0001\}$ basal planes of $\mathrm{TiB}_{2}$. This is the same set of planes on which athermal heterogeneous nucleation of $\alpha$-Al occurs ${ }^{[19,47]}$ : primary $\alpha$-Al may have initially covered the exposed $\{0001\}$ planes at higher temperature, earlier stage of solidification, but the $\alpha$-Al may remelt near the eutectic 


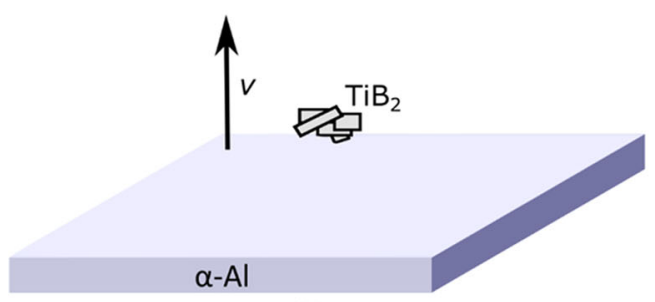

(a)

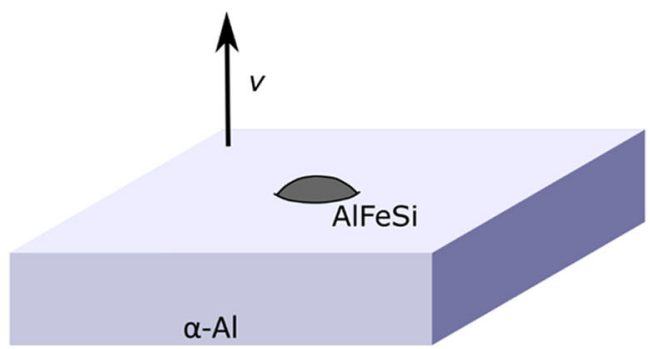

(c)

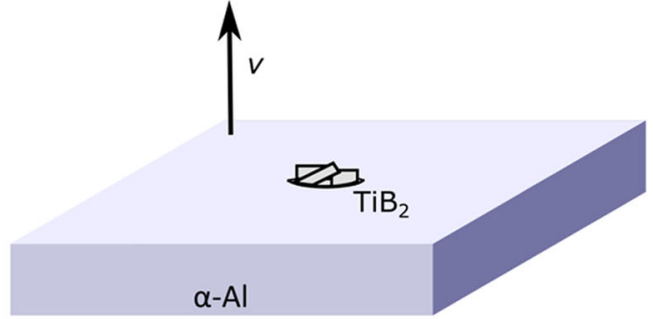

(b)

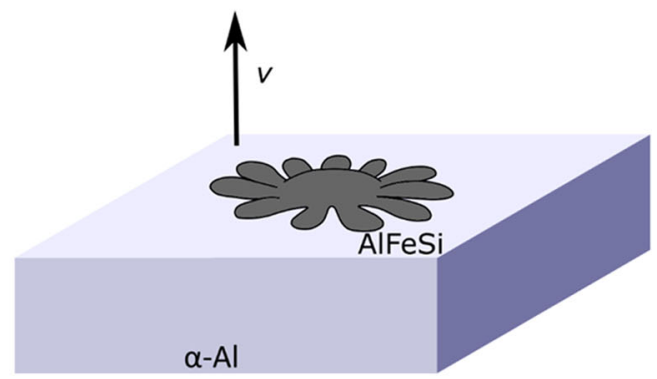

(d)

Fig. 8-A schematic showing the proposed mechanism of how $\mathrm{TiB}_{2}$ clusters influence the intermetallic phase formation: $(a)$ an inactive $\mathrm{TiB}_{2}$ cluster ahead of an advancing liquid/ $\alpha-\mathrm{Al}$ interface, $\mathrm{Si}$, and $\mathrm{Fe}$ rejected into the liquid; $(b)$ impingement of the $\mathrm{TiB}_{2}$ cluster by the advancing liquid/ $\alpha-\mathrm{Al}$ interface, and the cluster is partially wetted/engulfed; $(c)$ classical or athermal heterogeneous nucleation of AlFeSi on exposed facets of $\mathrm{TiB}_{2}$ in eutectic reaction, followed by onset of free growth for AlFeSi if nucleation is athermal; $(d)$ the AlFeSi spreads along the liquid/ $\alpha$ - $\mathrm{Al}$ interface and the periodic eutectic structure starts to appear. This gives rise to the $\alpha_{c}$-AlFeSi lamellae or $\beta$-AlFeSi rake structures observed in extracted particles, and the partial engulfment of $\mathrm{TiB}_{2}$ clusters leads to the observation of exposed $\mathrm{TiB}_{2}$ clusters in these $\mathrm{AlFeSi}$ structures after the dissolution of $\alpha-\mathrm{Al}$ in the extraction process.

temperature(s) because of the nonequilibrium build-up of $\mathrm{Si}$ and $\mathrm{Fe}$ in the residual liquid and insufficient time for the solid $\alpha$-Al to adjust its solute concentration by diffusion. Consequently, the $\mathrm{TiB}_{2}\{0001\}$ planes that were initially obscured by $\alpha$-Al may be reexposed to the $\mathrm{Fe}$ - and Si-enriched liquid and become available for nucleation of $\mathrm{AlFeSi}$ intermetallic phases.

As observed in Figures 5 and $7, \mathrm{TiB}_{2}$ clusters were associated with the formation of both intermetallic types: the formation tendency for intermetallic of a given type, in this case either $\alpha_{c}-\mathrm{AlFeSi}$ or $\beta$-AlFeSi, on the exposed facets will depend on the local liquid composition immediately adjacent to the $\mathrm{TiB}_{2}$ clusters, which may vary significantly from place to place as liquid is or is not interconnected through the extended interdendritic channels, the extent of which will depend on the shape and size of the primary $\alpha$-Al grains. ${ }^{[51]}$

In the case of cubic $\alpha_{c}$-AlFeSi, the surface energies of the principal facet faces are likely to be near isotropic. The critical radius of a $\alpha_{c}$-AlFeSi nucleus forming on a foreign substrate, in this case the exposed $\{0001\}$ planes on a cluster of $\mathrm{TiB}_{2}$, at an undercooling of $\Delta T_{\mathrm{AlFeSi}}$ follows a modified version of Eq. [3] ${ }^{[16,17]}$ :

$$
r_{\mathrm{AlFeSi}}^{*}=\frac{2 \cdot \gamma_{\mathrm{L} / \mathrm{AlFeSi}}}{\Delta S_{V_{\mathrm{AlFSi}}} \cdot \Delta T_{\mathrm{AlFeSi}}}
$$

where $\gamma_{\mathrm{L} / \mathrm{AlFeSi}}$ is the free energy per unit area of the liquid $/ \alpha_{c}$-AlFeSi interface and $\Delta S_{V_{\mathrm{AlF} \text { esi }}}$ is the entropy of fusion per unit volume. In the case of monoclinic $\beta$-AlFeSi, an additional geometric factor is likely to be necessary to take into account the anisotropy in surface energies on the different exposed facets. The observation that $\beta$-AlFeSi shows no strong preferential nucleation sites in the absence of grain refiners ${ }^{[38]}$ supports that nucleation of $\beta$-AlFeSi is difficult and requires a high undercooling, and the availability of $\mathrm{TiB}_{2}$ clusters at the liquid $/ \alpha$-Al interface reduces the energy barrier to nucleation. Nevertheless if the composition of liquid ahead of the liquid $/ \alpha$-Al interface as 'seen' by the exposed $\mathrm{TiB}_{2}$ facets, $\mathrm{C}^{*}$, is of a concentration such that $\Delta T_{\beta-\mathrm{AlFeSi}} \gg \Delta T_{\alpha-\mathrm{AlFeSi}}$, this anisotropy contribution to undercooling might be small, and nucleation of $\beta$-AlFeSi is preferred over $\alpha_{c}-\mathrm{AlFeSi}$.

It is likely that the proposed phenomenon of partial engulfment of inactive $\mathrm{TiB}_{2}$ clusters at the liquid/ $\alpha$-Al interface would be applicable to other $\mathrm{Al}$ systems and that the exposed $\mathrm{TiB}_{2}$ facets could similarly provide nucleation sites for other intermetallic type and facilitate eutectic reactions; however the effectiveness of such $\mathrm{TiB}_{2}$ clusters in nucleating other intermetallic type would almost certainly differ depending on various factors such as lattice mismatch.

\section{Cooperative and divorced growth of the Al/AlFeSi} eutectic

Once nucleation is catalyzed in the Fe- and Si-rich liquid pockets, further nucleation is unlikely (unless the liquid becomes further subdivided), and the $\mathrm{AlFeSi}$ phase begins to grow along the liquid/ $\alpha$-Al interface (Figure 8(d)), with $\alpha$-Al/AlFeSi initially seeking to grow side-by-side in a classical cooperative eutectic reaction, resulting in the recurring, characteristic structures observed among extracted AlFeSi particles. As there is 

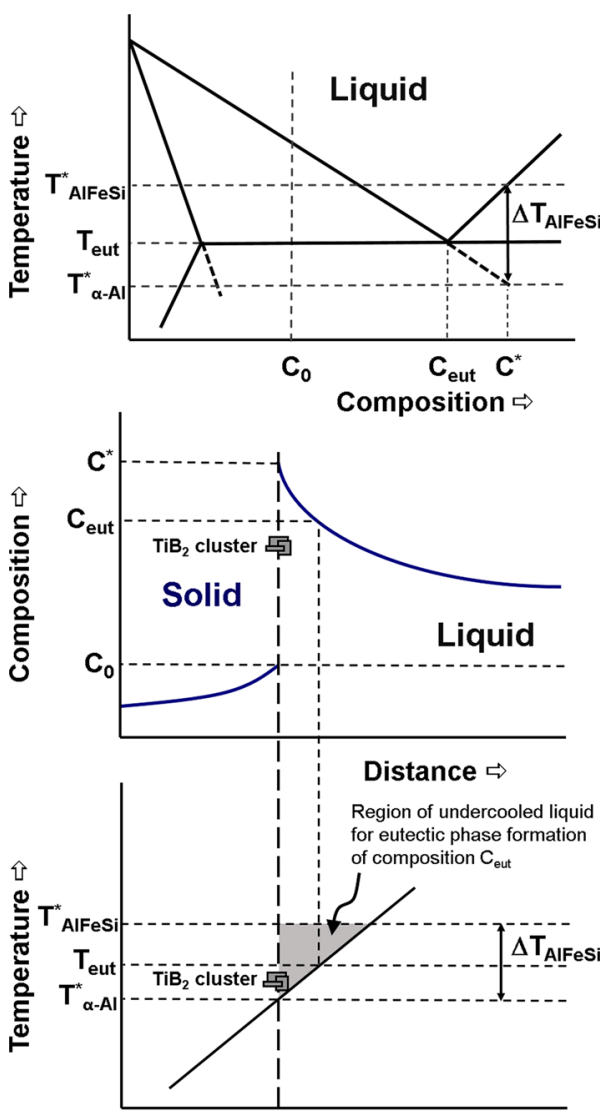

Distance 5

Fig. 9-A schematic showing a hypothetical phase diagram where a small fraction of metastable liquid is cooled to $T_{\alpha-A l}^{*}$, below the equilibrium eutectic temperature, and the resulting solute and temperature profile, at the point of AlFeSi nucleation. An impinged $\mathrm{TiB}_{2}$ cluster is included at the liquid $/ \alpha-\mathrm{Al}$ interface to illustrate the undercooling, $\Delta T_{\mathrm{AlFeS}}$, which the cluster experiences in the liquid immediately ahead. $\mathrm{C}_{0}$ is the overall alloy composition, $\mathrm{C}_{\text {eut }}$ is the eutectic composition and $\mathrm{C}^{*}$ is the liquid composition at the liquid/ $\alpha$-Al interface, $\mathrm{k}$ is the partition coefficient, $T_{\text {eut }}$ is the equilibrium $\mathrm{AlFeSi}$ phase eutectic temperature, $T_{\mathrm{AlFeSi}}^{*}$ is the liquidus temperature of $\mathrm{AlFeSi}$ at $\mathrm{C}^{*}$, and $T_{\alpha-A l}^{*}$ is the extrapolated liquidus temperature of $\alpha-\mathrm{Al}$ at $\mathrm{C}^{*}$.

already solute pile-up at the liquid/ $\alpha$-Al interface, short-range diffusion of $\mathrm{Al}, \mathrm{Fe}$, and $\mathrm{Si}$ is relatively easy and the product phases of the eutectic reaction $(\alpha-\mathrm{Al}$, $\mathrm{AlFeSi})$ grow cooperatively, in either a regular $(\alpha-\mathrm{Al} /$ $\left.\alpha_{c}-\mathrm{AlFeSi}\right)$ or irregular manner $(\alpha-\mathrm{Al} / \beta-\mathrm{AlFeSi}) .{ }^{[52-54]}$

As this is a relatively dilute alloy overall, there will be a relatively high volume fraction of preexisting primary $\alpha-\mathrm{Al}$ when the eutectic reaction(s) take place, with the last remaining liquid likely to be in the form of thin films delineating the $\alpha-\mathrm{Al}$ cells/dendrites. When the diffusion distance between $\alpha-\mathrm{Al}$ and $\mathrm{AlFeSi}$ is comparable with, or smaller than, that required for cooperative eutectic growth, there is no energy gain from forming triple junctions between the liquid, $\alpha-\mathrm{Al}$ and $\mathrm{AlFeSi}$, and $\mathrm{AlFeSi}$ and $\alpha$-Al will then grow independently as divorced eutectic, i.e. the intermetallic growth deviates from the classical lamellar/duplex structure to thin plates. The divorced growth of $\beta-\mathrm{AlFeSi}$ is in good qualitative agreement with synchrotron studies of the dynamics of $\beta-\mathrm{AlFeSi}$ growth in $\mathrm{Al}-\geq 7.5 \mathrm{Si}-\geq$ $3.5 \mathrm{Cu}-\geq 0.6 \mathrm{Fe} .^{[37,38]}$

\section{CONCLUSIONS}

Microstructural features have been identified as the initiation points for $\beta$-AlFeSi intermetallic compound (IMC) particle formation using extraction from an inoculated aluminum casting, and clusters of $\mathrm{TiB}_{2}$ grain refiner particles were commonly colocated with the same particular IMC features. Initiation points for $\alpha_{c}$-AlFeSi formation were also distinguished, showing the characteristic lamellar structure, in the same casting even when the overall intermetallic phase content was mainly of $\beta$-AlFeSi; again these initiation points were commonly associated with $\mathrm{TiB}_{2}$ particle clusters. Consequently, the association of $\mathrm{TiB}_{2}$ with intermetallic phase was concluded to be not $\alpha_{c^{-}}$or $\beta$-AlFeSi phase specific. There was also morphological evidence to suggest that, under the set of casting conditions in this study, the initial growths of both intermetallic phases were by cooperative eutectic reaction before the reaction became de-coupled.

\section{ACKNOWLEDGMENTS}

The authors thank the U.K. Engineering and Physical Sciences Research Council for financial support (Grant EP/N007638/1). Andrew Lui would like to thank the members of the Oxford Materials Characterisation Service, past and present, for their support and encouragement.

\section{CONFLICT OF INTEREST}

The authors declare that they have no conflicts of interest.

\section{OPEN ACCESS}

This article is distributed under the terms of the Creative Commons Attribution 4.0 International License (http://creativecommons.org/licenses/by/4.0/), which permits unrestricted use, distribution, and reproduction in any medium, provided you give appropriate credit to the original author(s) and the source, provide a link to the Creative Commons license, and indicate if changes were made.

\section{REFERENCES}

1. S.K. Das: in Aluminium Alloys 2006, PTS 1 And 2: Research Through Innovation and Technology, vol. 519-521, W.J. Poole, M.A. Wells, and D.J. Lloyd, eds., Materials Science Forum, 2006, pp. 1239-44.

2. M.H. Mulazimoglu, A. Zaluska, J.E. Gruzleski, and F. Paray: Metall. Mater. Trans. A, 1996, vol. 27A (4), pp. 929-36. 
3. G. Sha, K.A.Q. O'Reilly, B. Cantor, J.M. Titchmarsh, and R.G. Hamerton: Acta Mater., 2003, vol. 51 (7), pp. 1883-97.

4. C.H. Caceres and J.A. Taylor: Metall. Mater. Trans. B, 2006, vol. 37B (6), pp. 897-903.

5. S. Zajac, B. Hutchinson, A. Johansson, and L.O. Gullman: Mater. Sci. Technol., 1994, vol. 10 (4), pp. 323-33.

6. S. Shankar, Y.W. Riddle, and M.M. Makhlouf: Acta Mater., 2004, vol. 52 (15), pp. 4447-60.

7. N.C.W. Kuijpers, F.J. Vermolen, C. Vuik, P.T.G. Koenis, K.E. Nilsen, and S. van der Zwaag: Mater. Sci. Eng. A, 2005, vol. 394A (1-2), pp. 9-19.

8. D.G. McCartney: Int. Mater. Rev., 1989, vol. 34 (5), pp. 247-60.

9. R. Nadella, D.G. Eskin, Q. Du, and L. Katgerman: Prog. Mater. Sci., 2008, vol. 53 (3), pp. 421-80.

10. B. Cantor: Philos. Trans. R. Soc. A, 2003, vol. 361A (1804), pp. 409-16.

11. J.W. Christian: The Theory of Transformations in Metals and Alloys, Pergamon Press, Oxford, 1975.

12. A.L. Greer, A.M. Bunn, A. Tronche, P.V. Evans, and D.J. Bristow: Acta Mater., 2000, vol. 48 (11), pp. 2823-35.

13. K.A.Q. O'Reilly and B. Cantor: Acta Metall. Mater., 1995, vol. 43 (2), pp. 405-17.

14. D. Turnbull: J. Appl. Phys., 1950, vol. 21 (10), pp. 1022-28.

15. A.M. Bunn, P.V. Evans, D.J. Bristow, and A.L. Greer: in Light Metals 1998, B.J. Welch, ed., Minerals, Metals \& Materials Society, 1998 pp. 963-68.

16. W. Kurz and D.J. Fisher: Fundamentals of Solidification, Trans Tech Publications, Switzerland, 1992.

17. A.L. Greer: Philos. Trans. R. Soc. A, 2003, vol. 361 A (1804), pp. 479-94.

18. E. Liotti, C. Arteta, A. Zisserman, A. Lui, V. Lempitsky, and P.S. Grant: Sci. Adv., 2018, 4 (4), eaar4004.

19. T.E. Quested and A.L. Greer: Acta Mater., 2005, vol. 53 (9), pp. 2683-92.

20. T.E. Quested and A.L. Greer: Acta Mater., 2004, vol. 52 (13), pp. 3859-68.

21. I.G. Davies, J.M. Dennis, and A. Hellawell: Metall. Trans., 1970, vol. 1 (1), pp. 275-80.

22. X.G. Chen: in Light Metals 1998, B.J. Welch, ed., Minerals, Metals \& Materials Society, 1998 pp. 1071-76.

23. X.G. Chen: in Light Metals 1999, C.E. Eckert, ed., Minerals, Metals \& Materials Society, 1998, pp. 803-809.

24. M.W. Meredith, A.L. Greer, and P.V. Evans: in Solidification Processing 1997: Proceedings of the 4th Decennial International Conference on Solidification Processing, J. Beech and H. Jones, eds., University of Sheffield, Sheffield, 1997, pp. 541-45.

25. M.W. Meredith, A.L. Greer, and P.V. Evans: in Light Metals 1998, B.J. Welch, ed., Minerals, Metals \& Materials Society, 1998, pp. $977-82$.

26. M.W. Meredith, J. Worth and R.G. Hamerton: in Aluminium Alloys 2002: Their Physical And Mechanical Properties PTS 1-3, vol. 396-4, P.J. Gregson and S.J. Harris, eds., Materials Science Forum, 2002, pp. 107-12.

27. M.W. Meredith, A.L. Greer, P.V. Evans, and R.G. Hamerton: in Light Metals 1999, C.E. Eckert, ed.,. Minerals, Metals \& Materials Society, 1998, pp. 811-17.

28. I. Davidson: DPhil Thesis, Department of Materials, University of Oxford, UK, 2006.

29. G. Sha: DPhil Thesis, Department of Materials, University of Oxford, UK, 2001.
30. G. Sha, K.A.Q. O'Reilly, B. Cantor, R.G. Hamerton, and J. Worth: Aluminium Alloys: Their Physical And Mechanical Properties, PTS 1-3, vol. 331-3, E.A. Starke, T.H. Sanders, and W.A. Cassada, eds., Materials Science Forum, 2000, pp. 253-58.

31. The Aluminum Association: Standard Test Procedure for Aluminum Alloy Grain Refiners: TP-1, The Aluminum Association, Washington DC, 1990.

32. C.D. Mayes, D.G. McCartney, and G.J. Tatlock: Mater. Sci. Eng. A, 1994, vol. 188A, pp. 283-90.

33. B. Cantor and K.A.Q. O'Reilly: Solidification and Casting, Institute of Physics Publishing, Bristol, 2003.

34. C.J. Simensen, P. Fartum, and A. Andersen: Fresenius Zeitschrift Fur Analytische Chemie, 1984, vol. 319 (3), pp. 286-92.

35. M. Cooper: Acta Crystallogr., 1967, vol. 23 (6), pp. 1106-07.

36. A. Lui: DPhil Thesis, Department of Materials, University of Oxford, UK, 2009.

37. S. Terzi, J.A. Taylor, Y.H. Cho, L. Salvo, M. Suery, E. Boller, and A.K. Dahle: Acta Mater., 2010, vol. 58 (16), pp. 5370-80.

38. C. Puncreobutr, A.B. Phillion, J.L. Fife, P. Rockett, A.P. Horsfield, and P.D. Lee: Acta Mater., 2014, vol. 79, pp. 292303 .

39. Z. Fan, Y. Wang, Y. Zhang, T. Qin, X.R. Zhou, G.E. Thompson, T. Pennycook, and T. Hashimoto: Acta Mater., 2015, vol. 84, pp. 292-304.

40. Y. Xu, D. Casari, Q. Du, R.H. Mathiesen, L. Arnberg, and Y. Li: Acta Mater., 2017, vol. 140, pp. 224-39.

41. S. Kumar, P.S. Grant, and K.A.Q. O'Reilly: Metall. Mater. Trans. A, 2016, vol. 47A (6), pp. 3000-14.

42. S. Kumar and K.A.Q. O'Reilly: Mater. Charact., 2016, vol. 120, pp. 311-22.

43. T. Smith, K.A.Q. O'Reilly, S. Kumar, and I.C. Stone: Metall. Mater. Trans. A, 2013, vol. 44A (11), pp. 4866-71.

44. W. Khalifa, F.H. Samuel, J.E. Gruzleski, H.W. Doty, and S. Valtierra: Metall. Mater. Trans. A, 2005, vol. 36A (4), pp. 1017-32.

45. J. Rakhmonov, G. Timelli, and F. Bonollo: Metall. Mater. Trans. A, 2016, vol. 47A (11), pp. 5510-21.

46. D. Shu, B. Sun, J. Mi, and P.S. Grant: Acta Mater., 2011, vol. 59 (5), pp. 2135-44.

47. P. Schumacher and A.L. Greer: Mater. Sci. Eng. A, 1994, vol. 181A, pp. 1335-39.

48. M.X. Zhang, P.M. Kelly, M.A. Easton, and J.A. Taylor: Acta Mater., 2005, vol. 53 (5), pp. 1427-38.

49. S. Akamatsu, S. Moulinet, and G. Faivre: Metall. Mater. Trans. A, 2001, vol. 32A (8), pp. 2039-48.

50. J.A. Dantzig and M. Rappaz: Solidification, EPFL Press, Switzerland, 2016.

51. S. Feng, E. Liotti, A. Lui, S. Kumar, A. Mahadevegowda, K.A.Q. O'Reilly, and P.S. Grant: Scr. Mater., 2018, vol. 149, pp. $44-48$.

52. G.A. Chadwick: Metallography of Phase Transformations, Butterworths, London, 1972.

53. K.A. Jackson and J.D. Hunt: Trans. Metall. Soc. AIME, 1966, vol. 236 (8), pp. 1129-42.

54. F. Paray, B. Kulunk, and J. Gruzleski: Mater. Sci. Technol., 1996, vol. 12 (4), pp. 315-22.

Publisher's Note Springer Nature remains neutral with regard to jurisdictional claims in published maps and institutional affiliations. 